\title{
A Comparison of Personal Values of Chinese Accounting Practitioners and Students
}

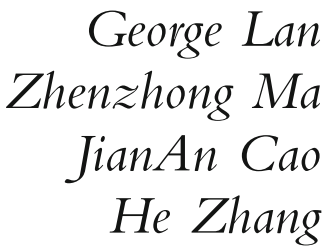

\begin{abstract}
This study examines the personal values and value types of Chinese accounting practitioners and students, using the values survey questionnaire developed and validated by Schwartz (1992, Advances in Experimental Social Psychology 25, 1-65). A total of 454 accounting practitioners and 126 graduate accounting students participated in the study. The results show that Healthy, Family Security, Self-Respect, and Honoring of Parents and Elders are the top four values for both accounting practitioners and accounting students, although these values are not ranked in the same order. Social Power, An Exciting Life, Devout, and Accepting My Portion in Life are the lowest rated four values for the accounting practitioners whereas Devout, An Exciting Life, Detachment, and Accepting My Portion in Life form the bottom four values for the accounting students. Both accounting practitioners and students ranked Security as the highest value type and Tradition as the lowest one, and the students rated Self-Direction as significantly more important than the practitioners. With respect to gender differences, both the male accounting practitioners and students rated the value type Achievement significantly higher than their female counterparts and there were several significant gender differences in personal values for both accounting practitioners and students. In addition, the perceived values are linked to social and cultural factors as well as to the influence of Western values.
\end{abstract}

KEY WORDS: personal values, value types, Chinese accounting practitioners and students, Schwartz values questionnaire, social and cultural factors

\section{Introduction}

Corporate scandals and accounting irregularities in North America have dramatically underscored the importance of ethical considerations and personal values in the accounting profession and business world. As China opens its doors to the West and moves from a centralized economy to a market economy, business enterprises have expanded and flourished. At the same time, the work responsibilities of accountants have increased and the accounting profession is faced with the challenge of proper ethical conduct and considerations to provide information that is fair and useful for decision making by external decision makers and other stakeholders involved. Recently, accounting irregularities have affected many companies listed on China's stock markets, which have been punished for false accounting. The establishment of national accounting institutes and better education and training in ethics for current and potential accounting practitioners could play an important role in stamping out irregularities in China's accounting sector.

Accountants play an important role in Chinese society. They provide information that can facilitate better decision making in an organization and they attest to information reported by organizations, thus affecting investors' confidence in these organizations. The accounting profession had changed a lot after China joined the World Trade Organization in 2001. In order to form business partnerships with other countries and develop its market economy with Chinese characteristics, China reformed its accounting practices and standards. According to Islam and Gowing (2003), Chinese accounting profession is "going through a period of transition from "moral vacuum" to crystallization based on changed ethical perspectives." In particular, in early 2006, China's Ministry of Finance announced a set of new auditing and accounting standards, revised 
according to International Financial Reporting Standards (IFRS), and since the beginning of 2007 , China's publicly listed companies are required to abide by IFRS. China is stepping up its efforts to improve the quality of its accounting profession and there is a greater emphasis on professional conduct and ethics. At a recent meeting of China Association of Chief Financial Officers, Wang Jun, China's Vice Minister of Finance promoted training in the accounting sector to cultivate the professional morals of accountants. As values influence behavior, it is important to understand the values of accounting practitioners and accounting students, who will soon be entering the workforce.

Chinese traditional values have permeated Chinese society through thousands of years of Chinese history, but strong winds of change have been blowing over China during the last few decades. First, there was the revolution and social reform brought about by communism, which promoted national interest, collective good, and equality of the sexes. Second, the "One Child Policy," was adopted in the constitution in China since the late 70 s and the early 80s. As Chinese families are allowed to have only one child in most regions of China, for the first time in the long history of China, an entire generation of Chinese has been born without siblings. The single child is often pampered and treated like a "little emperor," replacing the elders as the centre of attention in the Chinese family. And because most parents can have only one child, they are forced to treat their daughters as well as they would treat their sons. Third, with the "open door" policy and recent unofficial endorsement of the capitalistic system, China has undergone significant changes both in its economy and in its culture. Business has expanded rapidly and there is an increase in the wealth of Chinese people. And in the last decade, events such as the return of Hong Kong to China, the development of Shenzhen Special Economic Zone, an increasing number of Chinese students who study in Western countries, and easier access to internet, all have some influences on Chinese people's personal values and value systems.

While many studies have examined the value orientations of accounting students, practitioners, and other business professionals among Western nations (Egri and Ralston, 2004; Giacomino and Akers, 1998; Lan et al., 2008; Swindle et al., 1987; Wilson et al., 1998), few, if any, have reported on personal values and value types of Chinese accounting practitioners and accounting students. The overall purpose of this study is to investigate the priorities in personal values and value types (sets of interrelated values) of Chinese accounting practitioners and accounting students and to determine the effect of gender on these priorities in values for both of these groups. In addition, we examine the linkage between social and cultural factors and the influence of Western values on the values and value types of both accounting practitioners and students. Although exploratory in nature, such a study provides us with a perspective of understanding Chinese accounting people, both current accounting practitioners and potential accounting practitioners, by investigating their cherished values and value types as well as their perceptions and world views underlying their decisions.

In the remaining sections of this paper, we present the theory and hypothesis development followed by the methodology. The results are then presented, followed by discussion and concluding remarks.

\section{Theory and hypothesis development}

\section{Values and review of relevant research}

There is no generally accepted definition of the term values. Rokeach (1973) defined values as enduring beliefs regarding personally or socially preferable specific modes of conduct (instrumental values) or end-states of existence (terminal values), which influence attitudes and behaviors. In addition, values have also been defined as general standards shaping our attitudes and beliefs and influencing our behavior (Posner et al., 1987) and as desirable goals of varying importance that serve as guiding principles in our lives (Schwartz, 1992).

Although there is no universal definition of the concept of values, it is generally agreed that an individual's behavior is shaped by his/her personal values. Williams (1968) argued that the value systems (value types) or sets of values are useful for explaining individual behaviors. According to Kohlberg's cognitive development model (1976), people at the high post conventional level of moral development internalize and act on universal values such as standards of justice and human rights. Feather (1988) claimed that 
personal values are at the core of an individual's personality and that they influence the individual's behavior or characteristics such as attitude, evaluation, judgments, decisions, commitment, and satisfaction. Ravlin and Meglino (1987) summarized the empirical evidence linking personal values to behavior such as managerial decisions. According to Jones (1991), the likelihood that individuals will engage in unethical behavior depends partly upon their personal values, which lead them to evaluate their actions. Douglas and Schwartz (1999) observed that the values held by students affected their ethical judgments and Douglas et al. (2001) found that for practicing accountants, ethical judgments in situations of high moral intensity are affected by personal values (measured with the Rokeach survey instrument) and by environment variables, such as the professional code of conduct and previous ethics instruction. In addition, Gandal et al. (2005) argued that values "influence individuals in their perceptions, interpretations of situations, and hence direct people in their decisions, choices, and behaviors." Although the decisions of accountants are a product of professional judgment, they are ultimately influenced by their values and hence an examination of the values and value types of accounting practitioners and students in China can be useful in understanding (and promoting) the ethical conduct of accounting profession in China.

Swindle et al. (1987) and Wilson et al. (1998) investigated the values of practicing Certified Public Accountants (CPAs) in the USA. Both studies used the Rokeach Value Survey. Swindle and colleagues (1987) found that for CPAs, the top three values ranked in descending order were Family Security, Self-Respect, and Happiness and the bottom three values were A World of Beauty, National Security, and Social Recognition. They concluded that the values of the CPAs in their study appear to be more personal-oriented as apposed to social-oriented. Similarly, Wilson et al. (1998) found that practicing CPAs focused on an achievement oriented value system.

Schwartz (1992) developed a personal value questionnaire, the Schwartz Values Questionnaire (SVQ), containing 56 values that differ in the motivational goals to which they are directed. From the values, Schwartz identified 10 value types that are motivationally distinct and likely to be universal because they are grounded in one or more of the three universal requirements of human existence with which the values help to cope. These are needs of individual as biological organisms, requisites of coordinated social interaction, and survival and welfare needs of groups. The 10 distinct value types form a circular structure and their structural relations have been validated in multinational research (Schwartz, 1992, 1994; Schwartz and Sagiv, 1995). For each of the value types, namely, Achievement, Benevolence, Conformity, Hedonism, Power, Security, Self-direction, Stimulation, Tradition, and Universalism, there are associated value concepts (see Appendix 1).

Research using the SVQ has yielded interesting results, both in accounting related fields and in nonaccounting fields. Surveying business majors at a medium Jesuit university in Midwest America with SVQ, Giacomino and Akers (1998) reported significant differences between the responses of the accounting and non-accounting majors for 13 values and five value types. Accounting majors, in particular, rated Family Security, Honest, and True Friendship (in descending order) as the three most important values in their lives while Accepting My Portion in Life, Social Power, and Detachment were the lowest rated. The four highest rated value types were Benevolence, Achievement, Hedonism, and Self-Direction, and the two lowest rated were Tradition (ninth) and Power. They also found significant differences between female and male accounting majors for the following seven values: Mature Love, Broadminded, Politeness, Wealth, Reciprocation of Favors, Authority, and Power. Only Mature Love and Broadminded were rated significantly higher by the females. With respect to value types, only one significant difference in rating was found, namely, male accounting majors placed more importance on Power than did the female accounting majors. In addition, Hassan et al. (2002) reported that accounting students placed the highest importance on the value type "Achievement" and the lowest importance on "Power." They observed minor differences in the value systems (types) of accounting students in terms of gender and age. And in a study of business professionals, Giacomino et al. (1999) found that the three most important values of Japanese business managers are Health, Family Security, and World at Peace, while the three least important are Preserving Public Image, Authority, 
and Detachment. Japanese managers rated most highly the value types Self-Direction, Security, and Hedonism, while Tradition, followed by Power, was the two lowest rated.

A fundamental principle of the codes of ethics of International Federation of Accountants (IFAC), which establishes ethical requirements for professional accountants in nations adhering to IFRS is the principle of integrity whereby a professional accountant is required to be straightforward and honest in all professional and business relationships. The IFAC code of Ethics goes on to state that integrity implies not merely honesty but fair dealing and truthfulness. Furthermore, Finnegan (1994) concluded that an individual's judgment of what is moral or not is affected by the extent to which honesty is valued by the individual. Given the importance of honesty for business and the accounting profession, several studies have examined the importance of that value. Giacomino and Akers (1998) noted that most studies of personal values and professional attributes have consistently placed Honest among the top three values (e.g., Fagenson, 1993; Finegan, 1994). In a more recent study of business undergraduate majors at a Canadian university, Lan et al. (2008), using the SVQ, found that Honest is ranked fourth, after Family Security, True Friendship, and Healthy.

Chinese cultural values and the influence of social reforms and Western values

Chinese traditional values, especially Confucianism, are ingrained in the Chinese way of life and affect Chinese people's perception of what is important and what is not. Chinese culture differs from Western cultures in its strong emphasis on discipline and obedience of individuals to the collective benefits. Kongzi (Confucius, circa 551-479 B.C.) emphasized responsibility and obedience, with advancement through personal merit, education, and dignified service. Confucianism has been a dominant and enduring influence on cultural values in China despite the economic and political upheavals in the last two centuries (Waldmann, 2000). It differs substantially from Western philosophical ways of thinking and behaving and is at the philosophical basis for the collectivist and power distance values prevalent in China (Whitcomb et al., 1998).

Hill and Huang (2005) argued that three basic values of Chinese culture are collectivism (focus on the group's welfare as opposed to that of the individual), high power distance (respect for and obedience to authority figures and elders who are viewed to be psychologically "far away" and acceptance of differences in power and status among people as normal) and intra-group harmony, and the rejection of open-conflict in personal relationships (a concern for 'saving face' and intra-group cohesion).

Modern China is a country in which the process of institutional transformation has left cultural values in a state of flux (Gao and Handley-Schachler, 2003). The gradual shift from central planning to a market economy has impacted not only resource allocation but also Chinese values (Whitcomb et al., 1998). There are three views regarding the impact of industrialization and economic development on the personal values of managers. The first view argues that when countries adopt the free enterprise capitalistic system of the West, they are exposed to Western personal value system and approach of doing business and will adopt ideological values of the Western culture (Child, 1981; Tan, 2002). The second view maintains that cultural differences persist and value systems will remain largely unchanged even if the country adopts capitalism (Hofstede, 1980; Kelly et al., 1987). A third approach recognizes that integration of cultural and ideological influences results in a unique value system that is impacted by both culture and the process of industrialization (Ralston et al., 1997; Whitely and England, 1977).

Generally speaking, there are three major rival value orientations in contemporary Chinese society: Chinese traditional values, represented in particular by Confucian teachings; Western values, represented by individualism and materialism, which have recently penetrated Chinese society and are having a great influence on Chinese people's everyday life, in particular, for the young generation; and a third type of values that is basically a combination of Chinese traditional values and some imported Western values, including communism and collectivism. Collectivism is part of Chinese traditional values, yet it becomes more dominant when China adopted communism as the major ideology promoted throughout the country when the communist party took the power in late 
1940s. These three groups of value orientations affect how the Chinese rank their personal values and value types.

\section{The impact of life and work experience}

In recent years, China had to cope with natural disasters such as flooding, earthquakes, and epidemics. In 2003, the Severe Acute Respiratory Syndrome (SARS) disease struck China violently, creating a major health scare and after SARS had subsided, the bird flu swept across most of China's districts. Currently, there are also growing concerns with environmental pollution, especially in large cities. Major threats to health and survival could enhance the importance of certain values and value systems such as Health and Family security to Chinese accounting practitioners as well as to students.

Compared with accounting students, Chinese accounting practitioners are at a different life stage in terms of cultural, political, economic, work, and family experiences and in a different stage of the human life cycle (middle adulthood, on average, as opposed to early adulthood for the students). Using the SVQ, Egri and Ralston (2004) studied the personal values of generation cohorts in both China and the U.S. Their sample consisted of 774 Chinese and 784 U.S. managers and professionals, representing four Chinese generations denoted in their study as Consolidation (1950-1965), Cultural Revolution (1966-1977), Social Reform (1978-present), and the Republican Era (1911-1949) and three U.S. generations (Generation X, Baby Boom and Silent Generation). Egri and Ralston found that the value orientations of the three Chinese generations since the establishment of Communist China in 1949 were significantly more open to change and selfenhancing but less conservative and self-transcendent than the Republican Era generation. On the other hand, the personal values of the U.S. generation cohorts are related to age with the exception of self-transcendence values. Egri and Ralston (2004) found that the most recent generations tend to have more entrepreneurial value orientations, compatible with organizational changes underway in China's state-owned sector.

As China develops into a major economic power, social competition in the world's most populous country is becoming intense. There is a lot of pressure on accounting students, many of whom are single child, a result of the One Child Policy, to succeed so that the family can survive in China's increasingly competitive market driven economy. Hence, the younger accounting students might put greater emphasis on the value type Achievement than the accounting practitioners.

The younger accounting students experience the impact of Western values greater than the older accounting practitioners. Many of the younger Chinese generation learn English as a second language; Western customs, traditions and holidays such as Christmas and Valentine's Day are becoming increasingly popular in China, especially among the young adults, many of whom appear to be "Westernizing." There is more freedom to express one's views even about government policies and less censorship of the media and the internet. The younger accounting students would attach more emphasis to the value type Self Direction than the practitioners.

Work and family experiences also differ between accounting practitioners and students. The human life cycle theory postulates that as people age, they tend to be more collectivistic than individualistic, more conservative than open to change, and more selftranscendent than self-enhancing (Erickson, 1997; Smith and Schwartz, 1997; Stevens-Long, 1990).

Based on the literature review and the discussion above, we propose the following hypotheses pertaining to the values and values systems of Chinese accounting practitioners and students to be empirically tested:

H1: Chinese accounting practitioners have different values from those of accounting students.

H2: Chinese accounting practitioners have different value types from those of accounting students.

\section{The impact of gender}

Researchers have been studying the impact of gender on personal values and value types mostly in Western countries. While gender differences have been observed in studies of the personal values and value types in several studies such as those by Giacomino and Akers (1998), Lindeman and Verkasalo 
(2005), Schwartz and Rubel (2005), and Schwartz (2006), a few, such as Fagenson (1993) and Lan et al. (2008), found that individuals' gender had very little difference on their value systems.

In their study of 670 university students, Lindeman and Verkasalo (2005) found that female students attached more importance to the value types universalism and benevolence and less to power than the males. And in a meta analysis of studies involving 77,528 participants representing adults in literate societies in 70 countries, Schwartz and Rubel (2005) concluded that males consistently attributed more importance than females to power, stimulation, hedonism, achievement, and self-direction value types, while females assigned more importance to benevolence and universalism value types and, to a lesser extent, security. Nevertheless, they argued that these differences were small, and gender typically explained less variance than age and much less than culture.

In China, the feudalism system lasted for several thousands of years and is still very influential in today's society, especially in the different roles played by male and female in the society. According to this system, men control the whole world and women are just auxiliaries to men. While it is important for males to succeed and be educated, there is an old Chinese saying, which states: "a learned woman is twice a fool." The criterion by which to judge a woman's success is the happiness of the family. For thousand of years, women had been taught the "Three Submissions and the Four Virtues": submission to father, to husband, and after father and husband's death, to the eldest son; the virtues of fidelity, physical charm, propriety in speech and action, and diligence in housework (Xinran, 2003).

During the Chinese Revolution, Chairman Mao proclaimed that "women can carry half the weight of the sky," thus in essence, affirming the worth of women. As a symbol of the equal status of both genders, most married women in contemporary China do not change their family names to those of their husbands. Many women are now attending schools and universities, are employed in professional jobs such as doctors, lawyers, and accountants, and are contributing to the economic support of their family. Furthermore, with the One Child Policy enforced in many areas of China, many parents are giving more worth to and providing more opportunities for their daughters to receive a good education and have a successful career. Hence, females in China are currently enjoying a degree of liberalism similar to those witnessed in the Western world and are an important part of the workforce.

However, China, on the whole, is still a society dominated by men. The male power society has not changed much; males still long for achievement greater than the females and although feminine independent consciousness is becoming stronger, the notion that it is better for women to stay at home and not surpass man are deeply ingrained in China. We propose the following hypotheses regarding the effect of gender on values and value types:

H3: Female accounting practitioners have different values from those of male accounting practitioners.

H4: Female accounting practitioners have different value types from those of male accounting practitioners.

H5: Female accounting students have different values from those of male students.

H6: Female accounting students have different value types from those of male students.

\section{Methodology}

The research instrument used in this study is the SVQ, which consists of 56 individual values with a brief description for each value. The SVQ is a widely used instrument for measuring personal values across many samples and cultures (Egri and Ralston, 2004; Eliason and Shubot, 1995; Schwartz and Rubel, 2005). It includes more values than prior value instruments and provides a more extensive coverage and analysis of values (Giacomino and Akers, 1998). In addition, it examines value types or systems (groups of related values) and according to Williams (1968), an individual's decision is more influenced by value types rather than by individual personal values. Furthermore, the SVQ provides not only a ranking but also a rating of values, thus providing an evaluation of not only the priorities but also the weights given to perceived values in an individual's life.

The SVQ was translated into Chinese and back translation was used to ensure the equivalency (for a copy of the English version of the SVQ questionnaire, 
see Giacomino and Akers, 1998 or Lan et al., 2008). Respondents were asked to circle a number on a scale of -1 to 7 that best described the importance of each of the 56 values, as a guiding principle in their life. According to the rating scale, " -1 " represents values opposed to one's values or guiding principles, " 0 " means that the value is not at all important; " 3 " means the value is important, and " 6 " means that the value is very important. Values are then grouped according to their corresponding value type (as in Appendix 1) and a mean score is computed for each value type. Demographic data were also gathered on age, gender, and years of full-time work experience.

Accounting practitioners were recruited from practitioners in six large cities in China: Xi'an, Nanjing, Shenzhen, Qingdao, Zhengzhou, and Xining. Some practitioners were taking continuing education or MBA courses at universities; other practitioners were recruited by mailing questionnaires to their work place (accounting firms, companies, and enterprises). A total of 650 questionnaires were distributed and 462 were returned, yielding a response rate of $71 \%$. Of these, eight were discarded because of missing data resulting in 454 usable responses for our sample of accounting practitioners.

Accounting students were recruited from those in the graduate accounting program at the School of Management, Xi'an Jiaotong University, a large university in central china with a well-recognized accounting and business program. Graduate accounting students were used in this study because accounting students enrolled at graduate level in China are closer to entering the accounting workforce than the undergraduate accounting students. Each respondent was given a small gift of approximately $10 \mathrm{RMB}$ (Chinese Yuan). The response rate with the students was $90 \%$ and the resulting sample consists of usable data from 126 accounting students.

\section{Results}

Table I reports demographic information about the sample size, mean age, gender distribution, and work experience of the two groups studied. Of the 454 accounting practitioners who participated in this study, 130 were male while 323 were female (one respondent did not state his/her gender). The mean age of the accounting practitioners was 35 years,
TABLE I

Demographic data

\begin{tabular}{lll}
\hline & $\begin{array}{c}\text { Accounting } \\
\text { practitioners }\end{array}$ & $\begin{array}{c}\text { Accounting } \\
\text { students }^{\mathrm{a}}\end{array}$ \\
\hline Sample size & $454^{\mathrm{b}}$ & 126 \\
Mean age & 35 & 25 \\
Males & $130(29 \%)$ & $47(37 \%)$ \\
$\begin{array}{l}\text { Females } \\
\begin{array}{l}\text { Work experience } \\
\quad \text { (in years) }\end{array}\end{array}$ & 11.1 & 79 \\
\hline
\end{tabular}

${ }^{a}$ Accounting students enrolled in a graduate accounting program.

${ }^{\mathrm{b}}$ One accounting practitioner did not declare gender.

with 11.1 years of averaged working experience. There were 126 accounting students who responded to the survey, with 47 males and 79 females. Their mean age was 25 years and they had 0.9 years of working experience on average. For both samples, there are a greater percentage of females than males, which reflects to a certain extent the greater proportion of women in the accounting profession in China (see Cao and Nie, 2002).

Table II indicates the values in the top and lowest semi-quartiles ( 7 highest values with ranks 1 to 7 and 7 lowest values with ranks 50 to 56) for Chinese accounting practitioners and accounting students. There does not seem to be much difference in the values considered to be the most important and least important by either group. Healthy, Family Security, Honoring of Parents and Elders, and Self Respect were ranked as the top four values for each group. Healthy is considered the most important and Family Security, the second most important of values. The violent attack of SARS in 2003 and the increasing air pollution in many cities could heighten the importance of health and family to the individual. In addition, as Chinese economy develops rapidly and enterprises increase in size and number, the job of the accounting practitioner is becoming more demanding and stressful. Under such circumstances, people become more anxious and despondent and are likely to place a great emphasis on health and family.

Honoring of Parents and Elders is ranked fourth by the practitioners and third by the students; this result differs from those obtained in the West (for 
TABLE II

Top and lowest semi-quartile values of Chinese accounting practitioners and students

\begin{tabular}{|c|c|c|c|c|c|}
\hline \multicolumn{3}{|c|}{ Accounting practitioners $(N=454)$} & \multicolumn{3}{|c|}{ Accounting students $(N=126)$} \\
\hline Values & Mean & Rank & Values & Mean & Rank \\
\hline Healthy & 5.84 & 1 & Healthy & 5.87 & 1 \\
\hline Family Security & 5.55 & 2 & Family Security & 5.56 & 2 \\
\hline Self-Respect & 5.19 & 3 & Honoring of Parents \& Elders & 5.26 & 3 \\
\hline Honoring of Parents \& Elders & 5.10 & 4 & Self-Respect & 5.19 & 4 \\
\hline Capable & 4.86 & 5 & Capable & 5.10 & 5 \\
\hline National Security & 4.74 & 6 & Pleasure & 4.87 & 6 \\
\hline Pleasure & 4.68 & 7 & Social Recognition & 4.87 & 6 \\
\hline Respect for Tradition & 2.84 & 50 & Authority & 2.94 & 50 \\
\hline Authority & 2.80 & 51 & Respect for Tradition & 2.64 & 51 \\
\hline Detachment & 2.48 & 52 & Social Power & 2.40 & 52 \\
\hline Social Power & 2.26 & 52 & Devout & 2.09 & 53 \\
\hline An Exciting Life & 2.01 & 54 & An Exciting Life & 2.03 & 54 \\
\hline Devout & 1.90 & 55 & Detachment & 1.97 & 55 \\
\hline Accepting My Portion in Life & 1.82 & 56 & Accepting My Portion in Life & 0.79 & 56 \\
\hline
\end{tabular}

example, Giacomino and Akers, 1998), where Honoring of Parents and Elders was not ranked near the top. In China, the attachment to family is quite strong; Honoring of Parents and Elders is one of the Chinese nation's traditional virtues. The ancient well-known Chinese thinker Meng Tsu (372-289 BC) once said: "Extend the respect of the old in your own family to those of other families; extend the love of the young in your own family to those of other families." Despite the One Child Policy resulting in youngsters without siblings being the focus of attention of the family, traditional respect for parents and older people remains strong.

Self-Respect and Pleasure are listed in the top semi-quartile of values for each group, indicating that the Chinese are also adopting Western cultures and values that focus on belief in one's own worth and gratification of desires.

Among the lowest ranked values for both groups are Accepting My Portion in Life, Devout, An Exciting Life, and Detachment. In Chinese society, seeking an exciting life is not important so long as the group succeeds. The ranking of Devout in the lowest four values is related to China's social background, where religions have never played an important role in Chinese society.

The fact that both groups rank Accepting My Portion in Life among the lowest of values also indicates that Chinese accounting people, just as in the Western countries, perceive that submitting to life's circumstances is not important. China's economy is developing at a fast speed, presenting many opportunities for the individual Chinese to become rich and successful in a short time. Celebrities are constantly in the media; the newspaper and television broadcast news of successful individuals every day, fuelling dreams and hopes of becoming another Bill Gates. Under such social environment, the accounting practitioners and students are no exception; they also hope to become successful through individual endeavor and are not willing to accept bad conditions and destiny's circumstances.

Honest, which is not tabulated, was ranked 12th for all practitioners with a rating of 4.52 and 10th for the students with a rating of 4.71. Although not ranked as high as studies in Western countries, Honest is considered to be important by both groups, indicating that accounting practitioners as well as students also perceive this value related to a primary principle of codes of ethics and professional conduct for accountants to be an important one in their lives.

In Table III, $t$-tests indicate that there are several significant differences between the values of accounting practitioners and students. Accounting 
TABLE III

$T$-test results of personal values of Chinese accounting practitioners and students with significant differences

\begin{tabular}{|c|c|c|c|c|}
\hline Values & $\begin{array}{c}\text { Accounting } \\
\text { practitioners }(N=454)\end{array}$ & $\begin{array}{c}\text { Accounting } \\
\text { students }(N=126)\end{array}$ & $T$-test & Sig. (2-tailed) \\
\hline Inner Harmony & 4.22 & 4.60 & -2.62 & $.01 \star \star$ \\
\hline Sense of Belonging & 4.15 & 4.51 & -2.61 & $.01 \star \star$ \\
\hline Meaning in Life & 4.36 & 4.67 & -2.23 & $.03 \star$ \\
\hline Reciprocation of Favors & 3.98 & 3.52 & 3.05 & $.00 \star \star$ \\
\hline Creativity & 4.05 & 4.42 & -2.62 & $.01 \star \star$ \\
\hline A World at Peace & 4.37 & 3.83 & 3.12 & $.00 \star \star$ \\
\hline Mature Love & 3.85 & 4.36 & -3.09 & $.00 \star \star$ \\
\hline Detachment & 2.48 & 1.97 & 2.63 & $.01 \star \star$ \\
\hline Social Recognition & 4.51 & 4.87 & -2.78 & $.01 \star \star$ \\
\hline Varied Life & 3.54 & 4.01 & -3.08 & $.00 \star \star$ \\
\hline True Friendship & 4.59 & 4.85 & -2.05 & $.04 \star$ \\
\hline Moderate & 3.53 & 3.92 & -2.82 & $.01 \star \star$ \\
\hline Choosing Own Goals & 4.50 & 4.84 & -2.80 & $.01 \star \star$ \\
\hline Accepting My Portion in Life & 1.82 & 0.79 & 4.89 & $.00 \star \star$ \\
\hline Obedient & 3.67 & 3.16 & 3.46 & $.00 \star \star$ \\
\hline Enjoying Life & 3.96 & 3.61 & 2.03 & $.04 \star$ \\
\hline Curious & 3.07 & 3.39 & -2.06 & $.04 \star$ \\
\hline Successful & 4.39 & 4.71 & -2.27 & $.02^{\star}$ \\
\hline
\end{tabular}

$\star$ Significant at the $5 \%$ level; ${ }^{\star}$ Significant at $1 \%$ level.

practitioners ranked Reciprocation of Favors, A World at Peace, Accepting my Portion in Life, Obedient, and Enjoying Life to be more important values than accounting students. On the other hand, accounting students placed more emphasis on Inner Harmony, Sense of Belonging, Meaning of Life, Creativity, Mature Love, Social recognition, Varied
Life, True Friendship, Moderate, Choosing Own Goals, Curious, and Successful than the accounting practitioners. The younger students are still searching for their place in society and are concerned with developing relationships; they care more for the deep emotional and spiritual intimacy (Mature Love) than the practitioners.

TABLE IV

Value types of Chinese accounting practitioners vs. students

\begin{tabular}{|c|c|c|c|c|c|}
\hline \multicolumn{3}{|c|}{ Accounting practitioners $(N=454)$} & \multicolumn{3}{|c|}{ Accounting students $(N=126)$} \\
\hline Value types & Mean & Rank & Value types & Mean & Rank \\
\hline Security & 4.61 & 1 & Security & 4.58 & 1 \\
\hline Hedonism & 4.32 & 2 & Conformity & 4.40 & 2 \\
\hline Benevolence & 4.30 & 3 & Self Direction & 4.38 & 3 \\
\hline Conformity & 4.23 & 4 & Achievement & 4.32 & 4 \\
\hline Universalism & 4.21 & 5 & Benevolence & 4.32 & 4 \\
\hline Achievement & 4.21 & 5 & Hedonism & 4.24 & 6 \\
\hline Self Direction & 4.15 & 7 & Universalism & 4.16 & 7 \\
\hline Power & 3.04 & 8 & Power & 3.12 & 8 \\
\hline Stimulation & 3 & 9 & Stimulation & 3.11 & 9 \\
\hline Tradition & 2.79 & 10 & Tradition & 2.66 & 10 \\
\hline
\end{tabular}




\section{TABLE V}

$T$-test results of value types of accounting practitioners and students with significant differences

\begin{tabular}{lcccc}
\hline Value types & $\begin{array}{c}\text { Practitioners } \\
(N=454)\end{array}$ & $\begin{array}{c}\text { Students } \\
(N=126)\end{array}$ & $\begin{array}{c}T \text {-test } \\
\begin{array}{c}\text { Sig. } \\
(2-\text { tailed })\end{array}\end{array}$ \\
\hline Self direction & 4.15 & 4.38 & -2.45 & $.01 \star \star$ \\
\hline
\end{tabular}

$\star \star$ Significant at the $1 \%$ level.

Table IV shows that the value type Security is ranked foremost by both groups indicating the high importance placed on safety, harmony, and stability of society, of relationships, and of the self by accounting practitioners as well as students. Conformity, which indicates restraint of actions and a tendency to follow norms, is ranked fourth by the practitioners and second by the students. Benevolence is ranked third by the practitioners and fourth by the students. Achievement is ranked in the mid-range for both accounting practitioners and students, whereas in the US studies of accounting students by Giacomino and Akers (1998) and Hassan et al. (2002), it is ranked near the top for both groups. Power, with a rating slightly above 3 for both groups, is ranked third from the bottom implying that personal success while important does not take priority over safety, harmony, and stability of society.
As shown in Table $\mathrm{V}$, accounting students value Self-direction, representing independent thought and choice of action, to be more important than the accounting practitioners. This difference in the rating of self-direction is significant at the $1 \%$ level. It is possible that the working accounting practitioners adhere to the collective notions of socialism more so than the younger students. In addition, the practitioners face a more complicated environment, are more realistic, and are more likely to realize that many factors may be beyond their control. Hence, they take a more balanced and less idealistic view of what achievement and self-direction really represent. The younger accounting students pursue excitement, novelty, choosing own goals, and deep emotional and spiritual intimacy, while the accounting practitioners who, on average, have worked for 11 years tend to be more realistic and accept their portion in life. Hence, with age and working experience, priorities shift in values and value types.

Tables VI and VII examine the gender differences in the values of the Chinese accounting practitioners. Both genders rank Healthy and Family Security as their top two values and there is little difference in the ranking of values found in the top and bottom semi-quartiles for both genders. When the ratings assigned to the 56 values are compared as in

TABLE VI

Top and lowest semi-quartile values of Chinese accounting practitioners by gender

\begin{tabular}{|c|c|c|c|c|c|}
\hline \multicolumn{3}{|l|}{ Male $(n=130)$} & \multicolumn{3}{|c|}{ Female $(n=323)$} \\
\hline Values & Mean & Rank & Values & Mean & Rank \\
\hline Healthy & 5.81 & 1 & Healthy & 5.86 & 1 \\
\hline Family Security & 5.57 & 2 & Family Security & 5.55 & 2 \\
\hline Honoring of Parents \& Elders & 5.35 & 3 & Self Respect & 5.18 & 3 \\
\hline Self Respect & 5.22 & 4 & Honoring of Parents \& Elders & 5.01 & 4 \\
\hline Capable & 5.06 & 5 & Capable & 4.78 & 5 \\
\hline National Security & 4.83 & 6 & National Security & 4.71 & 6 \\
\hline Honest & 4.81 & 7 & Pleasure & 4.7 & 7 \\
\hline Respect for Tradition & 2.95 & 50 & Respect for Tradition & 2.79 & 50 \\
\hline Authority & 2.88 & 51 & Authority & 2.76 & 51 \\
\hline Detachment & 2.47 & 52 & Detachment & 2.48 & 52 \\
\hline Social Power & 2.26 & 53 & Social Power & 2.25 & 53 \\
\hline An Exciting Life & 2.14 & 54 & Devout & 2.02 & 54 \\
\hline Devout & 1.63 & 55 & An Exciting Life & 1.96 & 55 \\
\hline Accepting My Portion in Life & 1.49 & 56 & Accepting My Portion in Life & 1.86 & 55 \\
\hline
\end{tabular}


TABLE VII

$T$-test results of values of male and female Chinese accounting practitioners with significant differences

\begin{tabular}{lcccc}
\hline Values & Males $(n=130)$ & Females $(n=323)$ & T-test & Sig. (2-tailed) \\
\hline Sense of Belonging & 3.89 & 4.25 & -2.28 & $.02^{\star}$ \\
A World at Peace & 4.08 & 4.49 & -2.28 & $.02^{\star}$ \\
Social Recognition & 4.73 & 4.42 & 2.13 & $.03^{\star}$ \\
A World of Beauty & 3.36 & 3.75 & -2.42 & $.02^{\star}$ \\
Ambitious & 4.42 & 3.98 & 2.90 & $.00^{\star \star}$ \\
Broad-Minded & 4.60 & 4.15 & 3.17 & $.00^{\star \star}$ \\
Daring & 3.71 & 3.34 & 2.14 & $.03^{\star}$ \\
Protecting the Environment & 3.91 & 4.22 & -2.10 & $.04^{\star}$ \\
Honoring of Parents \& Elders & 5.35 & 5.01 & 2.65 & $.01^{\star \star}$ \\
Capable & 5.06 & 4.78 & 2.01 & $.05^{\star}$ \\
Accepting My Portion in Life & 1.49 & 1.96 & -2.13 & $.03^{\star}$ \\
Honest & 4.81 & 4.40 & 2.77 & $.05^{\star}$ \\
Successful & 4.72 & 4.26 & 3.16 & $.00^{\star \star}$ \\
\hline
\end{tabular}

«Significant at the $5 \%$ level; $\star \star$ Significant $(2$-tailed) at $1 \%$ level.

Table VII, there are 13 significant differences in values. Honoring of Parents and Elders, ranked third by the males and fourth by the females (Table VI), is rated to be significantly more important by the males, as are the values Social Recognition, Ambitious, Broad-Minded, Daring, Capable, Honest, and Successful (Table VII). These differences are rooted in the Chinese culture. It is primarily the Chinese male's responsibility to honor the parents and family by being successful and socially recognized and to do so he needs to be capable, daring, and ambitious. A
Chinese woman, however successful, belongs to her husband's family and her success brings glory and honor to her in-law parents rather than hers. T-tests shown in Table VII indicate that, compared to the male accounting practitioners, the females attach more importance to the values of Sense of Belonging, A World at Peace, World of Beauty, Protecting the Environment, and Accepting My Portion in Life.

Table VIII shows the ranking in value types by gender for the accounting practitioners. Security is

\section{TABLE VIII}

Value types of Chinese accounting practitioners by gender

\begin{tabular}{|c|c|c|c|c|c|}
\hline \multicolumn{3}{|l|}{ Male $(n=130)$} & \multicolumn{3}{|c|}{ Female $(n=323)$} \\
\hline Value types & Mean & Rank & Value types & Mean & Rank \\
\hline Security & 4.56 & 1 & Security & 4.63 & 1 \\
\hline Benevolence & 4.45 & 2 & Hedonism & 4.37 & 2 \\
\hline Achievement & 4.42 & 3 & Benevolence & 4.23 & 3 \\
\hline Conformity & 4.36 & 4 & Universalism & 4.22 & 4 \\
\hline Hedonism & 4.22 & 5 & Conformity & 4.18 & 5 \\
\hline Universalism & 4.2 & 6 & Self Direction & 4.13 & 6 \\
\hline Self Direction & 4.2 & 6 & Achievement & 4.13 & 7 \\
\hline Stimulation & 3.15 & 8 & Power & 3.02 & 8 \\
\hline Power & 3.09 & 9 & Stimulation & 2.94 & 9 \\
\hline Tradition & 2.71 & 10 & Tradition & 2.82 & 10 \\
\hline
\end{tabular}

$\star$ None of the differences in ratings by gender are significant at $5 \%$ level. 
TABLE IX

$T$-test results of value types of male and female accounting practitioners with significant differences

\begin{tabular}{lcccc}
\hline Value types & $\begin{array}{c}\text { Males } \\
(n=130)\end{array}$ & $\begin{array}{c}\text { Females } \\
(n=323)\end{array}$ & T-test & $\begin{array}{c}\text { Sig. } \\
(2 \text {-tailed })\end{array}$ \\
\hline Achievement & 4.42 & 4.13 & 2.72 & $.01 \star$ \\
Benevolent & 4.45 & 4.23 & 2.45 & $.04 \star \star$
\end{tabular}

$\star$ Significant at the $1 \%$ level; $\star \star$ Significant at the $5 \%$ level.

ranked first and Tradition last by both genders. The two significant differences in value types, as shown in Table IX, relate to Achievement and Benevolent, which are both rated and ranked higher by the males.

The values in the top and lowest semi-quartiles for the male and female accounting students are reported in Table X. There are many common values and few differences. Healthy is ranked first and Accepting My Portion in Life last by both genders. For the males, Capable and Successful are ranked higher than for the females, whereas the latter group ranks Self Respect and Pleasure higher than the males. In the lowest semi-quartile, the four values of lowest importance are Exciting Life,
TABLE XI

$T$-test results of personal values of male and female accounting students with significant differences

\begin{tabular}{lccrc}
\hline Values & $\begin{array}{c}\text { Males } \\
(n=47)\end{array}$ & $\begin{array}{c}\text { Females } \\
(n=79)\end{array}$ & T-test & $\begin{array}{c}\text { Sig. } \\
(2 \text {-tailed })\end{array}$ \\
\hline Pleasure & 4.57 & 5.07 & -1.95 & $.05^{\star}$ \\
Creativity & 4.89 & 4.14 & 3.18 & $.00 \star \star$ \\
Mature Love & 3.79 & 4.70 & -3.26 & $.00 \star \star$ \\
Authority & 3.70 & 2.48 & 3.75 & $.00 \star \star$ \\
Social Justice & 4.47 & 3.95 & 1.99 & $.05 \star$ \\
Ambitious & 4.74 & 3.66 & 3.78 & $.00 \star \star$ \\
Daring & 3.68 & 3.05 & 2.10 & $.04 \star$ \\
Influential & 3.98 & 3.06 & 3.27 & $.00 \star \star$ \\
Healthy & 5.62 & 6.01 & -2.16 & $.03 \star$ \\
Responsible & 5.09 & 4.30 & 3.57 & $.00 \star \star$ \\
Successful & 5.21 & 4.42 & 3.44 & $.00 \star \star$ \\
\end{tabular}

$\star$ Significant at the $5 \%$ level; $\star \star$ Significant (2-tailed) at $1 \%$ level.

Detachment, Devout, and Accepting My Portion in Life (last one for both groups).

Among the differences in values that are statistically significant between genders (Table XI), male accounting students attach more importance to

TABLE X

Top and lowest semi-quartile personal values of Chinese accounting students by gender

\begin{tabular}{|c|c|c|c|c|c|}
\hline \multicolumn{3}{|l|}{ Male $(n=47)$} & \multicolumn{3}{|c|}{ Female $(n=79)$} \\
\hline Values & Mean & Rank & Values & Mean & Rank \\
\hline Healthy & 5.62 & 1 & Healthy & 6.01 & 1 \\
\hline Capable & 5.34 & 2 & Family Security & 5.70 & 2 \\
\hline Family Security & 5.32 & 3 & Honoring of Parents \& Elders & 5.24 & 3 \\
\hline Honoring of Parents \& Elders & 5.30 & 4 & Self Respect & 5.22 & 4 \\
\hline Successful & 5.21 & 5 & Pleasure & 5.05 & 5 \\
\hline Self Respect & 5.15 & 6 & Capable & 4.96 & 6 \\
\hline Responsible & 5.09 & 7 & Social Recognition & 4.84 & 7 \\
\hline Obedient & 3.02 & 50 & Respect for Tradition & 2.49 & 50 \\
\hline Respect for Tradition & 2.89 & 51 & Authority & 2.48 & 51 \\
\hline Social Power & 2.81 & 52 & Social Power & 2.15 & 52 \\
\hline An Exciting Life & 2.14 & 53 & Devout & 2.06 & 53 \\
\hline Detachment & 2.13 & 54 & An Exciting Life & 1.97 & 54 \\
\hline Devout & 2.13 & 54 & Detachment & 1.87 & 55 \\
\hline Accepting My Portion in Life & 1.00 & 56 & Accepting My Portion in Life & 0.67 & 56 \\
\hline
\end{tabular}


TABLE XII

Value types of Chinese accounting students by gender

\begin{tabular}{|c|c|c|c|c|c|}
\hline \multicolumn{3}{|l|}{ Male $(n=47)$} & \multicolumn{3}{|c|}{ Female $(n=79)$} \\
\hline Value types & Mean & Rank & Value types & Mean & Rank \\
\hline Achievement & 4.82 & 1 & Security & 4.60 & 1 \\
\hline Self Direction & 4.61 & 2 & Hedonism & 4.45 & 2 \\
\hline Security & 4.54 & 3 & Conformity & 4.36 & 3 \\
\hline Conformity & 4.48 & 4 & Self Direction & 4.25 & 4 \\
\hline Benevolence & 4.47 & 5 & Benevolence & 4.23 & 5 \\
\hline Universalism & 4.22 & 6 & Universalism & 4.12 & 6 \\
\hline Hedonism & 3.89 & 7 & Achievement & 4.03 & 7 \\
\hline Power & 3.57 & 8 & Stimulation & 2.97 & 8 \\
\hline Stimulation & 3.33 & 9 & Power & 2.84 & 9 \\
\hline Tradition & 2.76 & 10 & Tradition & 2.60 & 10 \\
\hline
\end{tabular}

TABLE XIII

$T$-test results of value types of male and female accounting students with significant differences

\begin{tabular}{lccrl}
\hline Value types & $\begin{array}{c}\text { Males } \\
(n=47)\end{array}$ & $\begin{array}{c}\text { Females } \\
(n=79)\end{array}$ & T-test & $\begin{array}{c}\text { Sig. } \\
(2 \text {-tailed })\end{array}$ \\
\hline Achievement & 4.82 & 4.03 & 4.63 & $.00^{\star \star}$ \\
Hedonism & 3.89 & 4.45 & -2.42 & $.02^{\star}$ \\
Power & 3.57 & 2.84 & 2.80 & $.01^{\star \star}$ \\
Self Direction & 4.61 & 4.25 & 2.18 & $.03^{\star}$ \\
\hline
\end{tabular}

$\star$ Significant at the $5 \%$ level; ${ }^{\star}$ Significant at $1 \%$ level.

Creativity, Social Justice, Ambitious, Daring, Influential, Responsible, and Successful than the females. On the other hand, females consider the following values to be more important than the males as guiding principles in their lives: Pleasure, Mature Love, and Healthy.

Table XII shows the ranking of the value types for accounting students by gender, while Table XIII reports the significant differences in the ratings assigned to them by the male and female accounting students. Achievement and Self Direction are ranked and rated significantly higher for the males than for the females, whereas the female accounting students ranked and rated Hedonism much higher than the males. Although Power is ranked eighth by the males and ninth by the females, it is considered significantly more important by the males.

\section{Discussions}

This study provides partial support for Hypothesis 1, which hypothesizes that Chinese accounting practitioners have different values from accounting students. It is supported for 18 of the 56 values (see Table III). Hypothesis 2, which states that the accounting practitioners have different value types than the accounting students, is supported for only one of the 10 value types, as shown in Table V. Therefore, the results of this study show more similarities than differences in the values and value types of the accounting practitioners and students.

When comparing the value systems of the accounting practitioners with those of the students, one can notice that the younger students place more emphasis on the value type of Self-direction than the relatively older accounting practitioners. Both groups rank Security as the top ranked value type, indicating that concerns for safety, harmony, and stability of society, of relationships and of self are foremost in Chinese accounting practitioners as well as students. An interesting point is that both accounting practitioners and students rank Conformity in the top four of the value types and rank Tradition last, indicating that while both groups consider maintaining society norms to be important, they also attach least importance to commitment and acceptance of the customs and ideas that traditional culture or religion impose on the self. Furthermore, while both groups consider Accepting My Portion in Life to be the least important value, the weight given to that value differ; the mean score is 0.79 for students and 1.82 for practitioners. This indicates that as the respondents get older and mature, they are more likely to accept the reality and become used to what is given in life.

When the values and value types of Chinese accounting practitioners are compared by gender, there are 13 values with significant differences (Table VII) and two significant differences $(p<.05)$ in value types between the male and female respondents, thus providing partial support for Hypotheses 3 and 4 . The predominant value orientations of Security and Benevolence for both male and female practitioners 
are more readily associated with a socialistic and collectivistic attitude than is the value type of Achievement, which is ranked lower by both groups.

For Chinese accounting students, Hypothesis 5, which states that values differ by gender, is supported for 10 out of the 56 values (Table X) and there are 4 value types with significant differences attributed to gender (Table XII), thus providing partial support for Hypothesis 6. With respect to value types, Achievement and Self-direction are given much more importance by the males than by the female students. Security was ranked third by the males and first by the females, indicating that for both genders, the safety, harmony, and stability of society, of relationships, and of self are very important. In the Giacomino and Akers (1998) study of US business students as well as the Lan et al. (2008) study of Canadian business majors, Security was ranked slightly below the middle by both genders, perhaps because there was lesser concern about the stability of the society in these Western countries.

The results from this study suggest the strong influence of major Chinese value orientations as discussed in previous sections. First of all, despite the revolution brought about by communism and the recent significant inroads of modernization and capitalization, Chinese traditional values, especially Confucian teachings, are still ingrained in the Chinese way of life. With no exception, Family Security and Honoring of Parents \& Elders are among the top ranked values for both groups (Family Security is ranked the 2nd most important value for both groups; Honoring of Parents and Elders is ranked the 4th most important value for accounting practitioners and the 3rd most important value for accounting students), which suggests that the Chinese accounting practitioners and students place much importance on their parents and family, a clear indicator of Chinese traditional values' influence. This is consistent with the values of Chinese society, where the collective good, especially the good of family and parents, is of utmost importance. As a result, for future studies that investigate Chinese ethics and the perception of ethics in China, this is an important factor that should be taken into consideration.

Second, the results suggest that collectivism and communism still have important influences on Chinese people's perception of what is important and what is not. With over fifty years of communism teaching and collectivism inculcation, Chinese people, in particular the older generations, place strong emphasis upon values related to the country and the people. As a result, National Security is ranked in the top semi-quartile of values for the accounting practitioners (the 6th most important value, see Table II) and ranked in 13th position for accounting students in our study. This difference in rankings could in part be attributed to the age difference between the accounting practitioners and students in that the older accounting practitioners are more affected by the communism teaching than the younger accounting students.

Third, our study also indicates the influence of traditional Western values on Chinese society. In part due to the open policy and the ongoing modernization process in China, many Western values and value systems have been introduced into China and many Chinese, especially Chinese students and the white-collar professionals, are greatly exposed to a large number of different values and value systems. Consequently, values centered on individual and individual interests have found their places in Chinese values and value systems. As shown in this study, Self-respect and Healthy (which in essence demonstrate individual's concern about their own interests), and to a less extent, Pleasure, are among the top ranked values for both cohorts. Although not among the top ranked values, Honest is considered to be important by both the accounting practitioners as well as students. The value type Tradition is ranked last by both accounting students and practitioners, suggesting a de-emphasis of traditional Chinese acceptance of normal and natural differences in power and status among individuals. This may not sound a ring in Westerners, but it is a symbol that Chinese people, in particular, the students and well-paid white-collar professionals have partially accepted traditional Western values. The concept of self becomes more important. Individuality, a strong characteristic of Western cultures, is arising among Chinese people, which will have a significant impact on Chinese society. It seems that while the West is experiencing a transformation in values from a self-oriented focus to a communityoriented focus (Pinac-Ward et al., 1995), the reverse appears to be true for China, where greater emphasis 
is now being placed on the Western values of individualism and self-awareness.

With respect to gender differences, Tables VI and $\mathrm{X}$ show that male and female accounting practitioners and students have similar perceptions in what constitutes the most and least important guiding principles in their lives, which again indicates the result of communism and collectivism teaching whereby males and females have been promoted to be of equal status in the last half century in China. Nevertheless, Tables VII and XI show that there are significant differences in values between the genders in both groups. When value types are considered by gender, there is a greater emphasis on Achievement by the males in both groups. The man must have a successful career, whereas few will care about the woman's success in her career. The woman must do well in both career and family and as this is difficult, most females will choose family over career.

\section{Conclusions}

This study examines personal values and value types of Chinese accounting practitioners and accounting students. Healthy and Family Security were ranked first and second, respectively, by both groups. SelfRespect and Honoring of Parents and Elders were ranked third and fourth by accounting practitioners and the order is reversed for accounting students. Security was the highest ranked value type for both groups. There were several gender differences in values for both accounting practitioners and students and the value type Achievement was rated significantly higher by males in both groups.

The personal values and value types of Chinese accounting practitioners and students are related to the Chinese cultural traditions, the impact of communism and social reforms, and to the influence of Western values that have penetrated into Chinese society. Our results seem to support the notion of the integration of traditional Chinese culture with Western ideological influences, resulting in values that are basically a combination of Chinese traditional values and some imported Western values. Recent events such as the SARS and bird flu epidemics seem to have enhanced the importance of the value Health to both the practitioners and students.

Of course, this study has its limitations. Although the data on accounting practitioners was gathered in five major cities, it may not be representative of the general population of accounting practitioners in China. In addition, the sample of students was from one university in central China, although the university has a well-recognized accounting and business program. In future study, larger and more randomized samples of accounting practitioners and students could be taken to obtain more generalizable results. The current study did not differentiate the responses of the practitioners by factors such as years of work experience or the position held and it is possible that these factors may affect personal values. There may also be a social desirability issue with the use of self-reported questionnaire information.

Nevertheless, this study has shed some light on the values considered important or less important by Chinese accounting practitioners and students. This research is useful to accounting firms and other potential employers to assess the extent to which they take into account the values and priorities of their male and female employees. Educators, business schools, and organizations in China could also include in their curricula, activities or courses that will evoke in accounting students and employees, values that are conducive to a wider social awareness and concern and to ethical behavior. Accounting academics in China can play a catalytic role in character training and development of the professional morals and ethics of future accountants. Further research in this domain will lead to a greater mutual understanding for the increasing number of Western organizations and business people doing or seeking to do business with Chinese organizations and people and will as well be useful for educators and accounting standard setting bodies in China.

\section{Acknowledgements}

This study was supported by the National Natural Science Foundation of China, Grant \#: 70471038 and by an Odette Research and Teaching Innovation Fund from the University of Windsor, Canada. The authors thank the anonymous reviewers for their comments on the manuscript. 


\section{Appendix 1}

Value Types

(Schwartz and Sagiv, 1995; Schwartz, 2006)

Values for Each Value Type Shown in Parentheses

Achievement: Personal success through demonstrating competence according to social standards (Successful, Capable, Ambitious, Influential, Intelligent). These emphasize active demonstration of successful performance in social interaction as one means to obtain social esteem.

Benevolence: Preservation and enhancement of the welfare of people with whom one is in frequent personal contact (Helpful, Honest, Forgiving, Loyal, and Responsible). These emphasize voluntary concern for the welfare of others in the family or other important group to achieve smooth social relationships, striving for true friendship and mature love.

Conformity: Restraint of actions, inclinations, and impulses likely to upset or harm others and violate social expectations or norms. (Politeness, Obedient, Self-Discipline, Honoring Parents and Elders). These reflect the need for self-restraint to avoid negative outcomes such as disrupting and undermining smooth interaction with a group.

Hedonism: Pleasure and sensuous gratification for oneself (Pleasure, Enjoying Life).

Power: Social status and prestige, preserving one's public image, control or dominance over people and resources (Social Power, Authority, Wealth). These describe elements of hierarchy in any legitimate social structure and a means to define social esteem.

Security: Safety, harmony and stability of society, of relationships, and of self. (Family Security, National Security, Social Order, Clean, Healthy, Reciprocation of Favors). These reflect both individual and group security.

Self-direction: Independent thought and actionchoosing, creating, exploring (Creativity, Self-respect, Freedom, Independent, Curious, Choosing Own Goals). These values indicate the importance of both independent thought and action and the need for mastery, control, and interactional autonomy.

Stimulation: Excitement, novelty, and challenge of life (Daring, a Varied Life, an Exciting Life). These relate to the need for a level of stimulation necessary to be active at an optimal not threatening level.
Tradition: Respect, commitment, and acceptance of the customs and ideas that traditional culture or religion impose of the self. (Humble, Accepting My Part in Life, Devout, Respect for Tradition, Moderate). These reflect the subordination of individual needs and the exercise of self-restraint to avoid disrupting expectations imposed by more abstract institutions such as religious and cultural customs.

Universalism: Understanding, appreciation, tolerance and protection for the welfare of all people and for nature (Broadminded, Wisdom, Social Justice, Equality, A World at Peace, A World of Beauty, Unity with Nature, Protecting the Environment). These values emphasize acceptance and just treatment of others with whom one is unfamiliar and who appear to be different.

Note: The value types include only those values found to be stable between genders and across countries. Those values not included in the value types are (in alphabetical order): A Spiritual Life, Detachment, Healthy, Inner Harmony, Intelligent, Mature Love, Meaning in Life, Preserving My Public Image, Sense of Belonging, Social Recognition and True Friendship.

\section{References}

Cao, J. and L. Nie: 2002, 'Research of the Composition of the Accountants in China', Friend of Accounting 1, 16-17.

Child, J. D.: 1981, 'Culture, Contingency and Capitalism in the Cross-national Study of Organization', in L. L. Cummings and G. M. Staw (eds.), Research in Organizational Behavior 3, (JAI Publishers, Greenwich, CT), pp. 303-356.

Douglas, P. C., R. A. Davidson and B. N. Schwartz: 2001, 'The Effect of Organizational Culture and Ethical Orientation on Accountants' Ethical Judgments', Journal of Business Ethics 34(2), 101-121.

Douglas, P. C. and B. N. Schwartz: 1999, 'Values as the Foundation for Moral Judgment: Theory and Evidence in an Accounting Context', Research on Accounting 5, 3-20.

Egri, C. P. and D. A. Ralston: 2004, 'Generation Cohorts and Personal Values: A Comparison of China and United States', Organization Science 1, 210-220.

Eliason, B. C. and D. B. Schubot: 1995, 'Personal Values of Exemplary Physicians: Implications for Professional Satisfaction in Family Medicine', The Journal of Family Practice 41(3), 251-256. 
Erikson, E. H.: 1997, The Life Cycle Completed (W.W. Norton, New York).

Fagenson, E.: 1993, 'Personal Value Systems of Men and Women Entrepreneurs Versus Managers', Journal of Business Venturing 8(5), 409-430.

Feather, N.: 1988, 'From Values to Actions: Recent Application of the Expectancy-Value Model', Journal of Psychology 40, 105-124.

Finnegan, M.: 1994, Ethics and Economics. Master's thesis, University College, Galway.

Gandal, N., S. Roccas, L. Sagiv and A. Wrzesniewski: 2005, 'Personal Value Priorities of Economists', Human Relations 58(10), 1227-1251.

Gao, S. S. and M. Handley-Schacter: 2003, 'The Influences of Confucianism, Feng Shui and Buddhism in Chinese Accounting History', Accounting Business \& Financial History 13(1), 41-68.

Giacomino, D. E. and M. Akers: 1998, 'An Examination of the Differences Between Personal Values and the Value Types of Female and Male Accounting and Nonaccounting Majors', Issues in Accounting Education 13, 565-584.

Giacomino, D. E., M. D. Akers and A. Fujita: 1999, 'Personal Values of Japanese Business Managers', Business Forum, Los Angeles 24, 9-15.

Hassan, M., K. Dhanani and A. Witherspoon: 2002, Personal Values of Accounting Students: Empirical Study. IBER Conference Proceedings, Las Vegas, Nevada.

Hill, R. E. and W. Huang: 2005, An Introduction to Chinese Culture and a Comparison to American Culture. Global Business Trends: Contemporary Readings (Proceedings of Academy of Business Administration), pp. 131-134.

Hofstede, G.: 1980, Culture's Consequences (Sage, Beverly Hills, CA).

Islam, M. and M. Gowing: 2003, 'Some Empirical Evidence of Chinese Accounting System and Business Management Practices from an Ethical Perspective', Journal of Business Ethics 42(4), 353-378.

Jones, T.: 1991, 'Ethical Decision Making by Individuals in Organizations: An Issue-Contingent Model', Academy of Management Review 79, 97-116.

Kelly, L., A. Whatley and R. Worthley: 1987, 'Assessing the Effects of Culture on Managerial Attitudes: A Three-Culture Test', Journal of International Business Studies 18(1), 17-31.

Kohlberg, L.: 1976, 'Moral Stages and Moralization: The Cognitive-Developmental Approach', in T. Lickona (ed.), Moral Development and Behavior: Theory, Research and Social Issues (Holt, Rinehart and Winston, New York), pp 31-53.

Lan, G., M. Gowing, S. McMahon, F. Rieger and N. King: 2008, 'A Study of the Relationship Between
Personal Values and Moral Reasoning of Undergraduate Business Students', Journal of Business Ethics 78, 121-139.

Lindeman, M. and M. Verkasalo: 2005, 'Measuring Values with the Short Schwartz's Value Survey', Journal of Personality Assessment 85, 170-178.

Pinac-Ward, S., D. Ward and T. E. Wilson Jr.: 1995, 'University Accounting Professors: An Examination of Personal Values', Accounting Educators Journal 7(1), 39-53.

Posner, B., W. Randolph and W. Schmidt: 1987, 'Managerial Values Across Functions: A Source of Organizational Problems', Group and Organization Studies 12(4), 373-385.

Ralston, D. A., D. H. Holt, R. H. Terpstra and K. C. Yu: 1997, 'The Impact of National Culture and Economic Ideology on Managerial Work Values: A Study of the US, Russia, Japan and China', Journal of International Business Studies 18(1), 107-177.

Ravlin, E. and B. Meglino: 1987, 'Effect of Values on Perception and Decision Making: A Study of Alternative Work Values Measures', Journal of Applied Psychology 72, 666-673.

Rokeach, M.: 1973, The Nature of Human Value (JosseyBass, San Francisco).

Schwartz, S. H.: 1992, 'Universals in the Content and Structure of Values: Theoretical Advances and Empirical Tests in Twenty Countries', Advances in Experimental Social Psychology 25, 1-65.

Schwartz, S. H.: 1994, 'Are There Universal Aspects in the Structure and Contents of Human Values?', Journal of Social Issues 50(4), 19-45.

Schwartz, S. H.: 2006, 'Basic Human Values: Theory Measurement, and Application', Revue Française de Sociologie 47(4).

Schwartz, S. H. and T. Rubel: 2005, 'Sex Differences in Value Priorities: Cross-Cultural and Multimethod Studies', Journal of Personality and Social Psychology 89(6), 1010-1028.

Schwartz, S. H. and L. Sagiv: 1995, 'Identifying CultureSpecifics in the Content and Structure of Values', Journal of Cross-Cultural Psychology 26, 92-116.

Smith, P. B. and S. H. Schwartz: 1997, 'Values', in C. Kagitcibasi and M. H. Segall (eds.), Handbook of Cross-cultural Psychology (Allen and Bacon, Boston), pp. 77-118.

Stevens-Long, J.: 1990, 'Adult Development: Theories Past and Future', in R. A. Nemiroff and C. A. Colarussso (eds.), New Dimensions in Adult Development (Basic Books, New York), pp 125-165.

Swindle, B., L. D. Phelps and R. Broussard: 1987, Professional Ethics and Values of Certified Public Accountants. The Woman CPA (April), p. 3. 
Tan, B.: 2002, 'Researching Managerial Values: A CrossCultural Comparison', Journal of Business Research 55(10), 815-821.

Waldmann, E.: 2000, 'Teaching Ethics in Accounting: A Discussion of Cross-Cultural Factors with a Focus on Confucianism and Western Philosophy', Accounting Education 9, 23-35.

Whitcomb, L. L., C. B. Erdener and C. Li: 1998, 'Business Ethical Values in China and the U.S', Journal of Business Ethics 17, 839-852.

Whitely, W. T. and G. W. England: 1977, 'Managerial Values as a Reflection of Culture and the Process of Industrialization', Academy of Management Journal 20(3), 439-453.

Williams, R. M. Jr.: 1968, 'The Concept of Values', in D. L. Sills (ed.), International Encyclopedia of Social Sciences (Macmillan, New York, NY).

Wilson, T. E., S. Pinac-Ward and D. R. Ward: 1998, 'CPA Values Analysis: Towards a Better Understand- ing of the Motivations and Ethical Attitudes of the Profession', in L. Ponemon (ed.), Research on Accounting Ethics (JAI Press, Greenwich, CT), 4, 201-210.

Xinran: 2003, The Good Women of China (Random House, Toronto), p. 114.

George Lan and Zhenzhong Ma Odette School of Business, University of Windsor, 401 Sunset Avenue, Windsor, Ontario, Canada N9B 3P4

E-mail:glan@uwindsor.ca

JianAn Cao and He Zhang School of Management, $X i$ 'an Jiaotong University, Xi'an, Shaanxi, China 